\title{
Assessment of Knowledge, Attitudes, and Practice on Contraceptive Use among Women Attending Family Planning Services in Some Health Centers of Muhima District Hospital, Rwanda
}

Kanyange Phoibe BSc, MPH, Tegera Mpamya Frederic BSc, MPH*, Joseph Ntaganira MD, DTM, MPH, PhD, Associate Professor

University of Rwanda, School of Public Health, College of Medicine and Health Sciences, Kigali-Rwanda

*Corresponding Author: Frederic Tegera Mpamya: allofreddy1975@gmail.com

Citation: Kanyange Phoibe, Tegera Mpamya Frederic , Joseph Ntaganira (2017) Assessment of Knowledge, Attitudes, and Practice on Contraceptive Use among Women Attending Family Planning Services in Some Health Centers of Muhima District Hospital, Rwanda 2(3).

Received: $24^{\text {th }}$ March, 2017

Accepted: $19^{\text {th }}$ May, 2017

Published: $14^{\text {th }}$ July 2017

Copyright: (c2017 This is an open access article under the terms of the Creative Commons

Attribution License, which permits unrestricted use, distribution, and reproduction in any medium, provided the original author and source are credited.

\section{Funding: The author(s) received} no specific funding for this work.

\section{Competing Interests: The} author have declared that no competing interests exists.

\section{Abstract}

Introduction: In developing countries, especially in Africa, reproductive health is a great concern to many stakeholders as maternal mortality and morbidity are very high compared to that in the developed world. Moreover, reproductive health knowledge and access to quality maternal health services in Africa are poor with significant health consequences. Appropriate reproductive health knowledge and attitude can empower women to access quality family planning services (preventive and curative), which are essential for improvement of women's reproductive health. Objectives: This research aimed to assess reproductive health knowledge, attitude, and practice on contraceptive use among women attending family planning services at Muhima district hospital. Methods and Materials: The study was cross-sectional in nature involving 326 randomly selected respondents among women attending family planning services at Muhima district hospital. The study instrument was a self-administered questionnaire. Data was analyzed using SPSS (Statistical Package for Social Science) statistics software 17.0 version. 
Hypothesis: Looking at the aforementioned objective, one may wonder if the health education on contraceptive use given by health staff of Muhima district hospital is well done; we may also wonder about reproductive health beliefs and determinants of contraceptive use among women attending the family planning service; and to what extent women in Muhima district hospital have access to health education on contraceptive use. Trying to find an interim response to this question, we have come to realize that the impact of belief in personal and community health practices is strong; but individual beliefs may not be scientifically true and as such, may make one rightly or wrongly access health care. Results: The majority of the respondents knew when pregnancy can occur and believed that having sex even once with a man may result in pregnancy. $90.0 \%$ of respondents had knowledge of benefits of family planning. Consideration about personal health $(86.0 \%)$ and husband's approval $(74.9 \%)$ were major determinants of respondents' use of contraceptives. Conclusions: Though respondents were knowledgeable about the benefits of family planning, there is the need for continuous education of women about reproductive health issues and integration of men's participation in the family planning program to increase utilization of family planning services at Muhima district hospital.

Keywords: Knowledge, Attitudes, Practice, Contraceptives, Family Planning.

\section{Introduction}

Reproductive health occupies a central position in the nature of health as well as the development of a given population. However, the critical events of reproductive health are usually found in women who, due to their biological function, invariably, bear the greater burden of the shortcomings of reproductive health such as unsafe motherhood or unsafe abortion.

In developing countries, especially in Rwanda, there is need to improve maternal and child health care services as most deaths of women during pregnancy or delivery are preventable. In the Revised National Health Policy of Rwanda, among the two identified critical factors in the current situation of the health status of the country are the following: the neonatal mortality rate is 37 deaths per 1,000 and post neonatal mortality is 49 deaths per 1,000 live births [1]. 
On the light of this, one of the key National Policy on Reproductive Health objectives is to reduce maternal morbidity due to pregnancy and childbirth by $50 \%$ [2]. At least 200 million women want to use safe and effective family planning methods, but they are unable to do so because they lack access to information and services or the support of their husbands and communities. And more than 50 million of the 190 million women who become pregnant each year undergo abortions. Many of these abortions are clandestine and performed under unsafe conditions [3].

The international community has agreed that reproductive choice is a basic human right. But without access to relevant information and high-quality services, that right cannot be exercised. In Malawi, in a study conducted in 2006, most of the respondents knew the different types of family planning methods and reported that health facilities had adequate stock of family planning supplies [4].

However, it was found that most of the women and men were not using any modern family planning methods. This is mostly due to the fact that the family planning methods are perceived as having side effects, such as prolonged menstruation, men's concerns about impotence and genital sores, weight gain or loss, and subsequent infertility. Traditional family planning methods were mostly used for infertility problems. It has been estimated that about half of the total demand for contraception in Malawi remains unmet and, consequently, approximately $22 \%$ of pregnancies are unwanted [5].

Family planning helps everyone (women, children, men, families). Specifically, it protects women from unwanted pregnancies, thereby saving them from high-risk pregnancies or unsafe abortions. Besides protecting women from high-risk pregnancies, other benefits accruing from family planning methods include prevention from cancers that might occur. Literature review shows that the advantages of proper family planning are enormous as high fertility rate has been linked with underdevelopment in developing countries. Therefore, the focus of this present study is to make a clear assessment of knowledge, attitude, and practice on contraceptive use among women attending family planning services at four health centers in Muhima district hospital.

In Rwanda, both the qualitative and quantitative data show that men have a strong influence over fertility decisions and that some women use family planning secretly. Determinants of reproductive health service use rest on the individual, household, service and community levels [6].

\section{Study Motivation}

Family planning is beneficial to everyone: women, men, children, families, nations, and the whole world in general. Specifically, it protects women from unwanted pregnancies, thereby saving them from high-risk pregnancies or unsafe abortions. If all women could avoid high-risk pregnancies, the number of maternal deaths could fall by one-quarter.

Rwanda, with its 322 inhabitants per $\mathrm{km}^{2}$, is one of the densely populated countries in Africa. Family planning in Rwanda in general and in the most of our particular present study constitutes a fundamental human right [7]. All methods of family planning are still beyond the reach of the population, while certain family planning services are often underemployed. In addition to numerous obstacles, many other reasons have not been yet elucidated as the origin of the underutilization of health services. 


\section{Conceptual Framework}

This chapter aims to review the critical points of current knowledge including substantive findings as well as theoretical and methodological contributions to the present study. Its ultimate goal is to bring the reader up to date with current literature on the study topic and form the basis for future research that may be needed in this area.

\section{Methods and Materials}

\section{Study Design}

This is a Descriptive cross-sectional exploratory study on women of reproductive age attending family planning clinic services in different health centers of Muhima district hospital during the period mid-July to end of August 2011.

\section{Study Area}

Muhima district hospital is located in Nyarugenge district in Kigali city. It has many health centers under its supervision. In total, it serves the entire population of the whole district of the Kigali city, mainly in reproductive health, maternal and child health, including family planning. The total population in the reproductive age $(15-49)$ period is 28036 .

\section{Sample Size Calculation}

For the calculation of the sample size, we used the Schwartz formula:

$$
N=\frac{z^{2} 1-a / 2 P(1-p)}{d^{2}}
$$

Here $N$ : sample size; $z^{2}$ : Z-score, the level of confidence at $95 \%$ in which it is recommended to be sure that the right population for sampling can be assumed at $\pm 5 \%(0.05)$ of the sample estimated; $p$ : prevalence estimated of the family planning methods used and $a$ : the level of precision, which is equal to $5 \%$.

$$
\frac{N \geq z^{2}(p)(1-p)}{a^{2}}=\frac{(1,96)^{2}(0.5(1-0.5)}{(0.05)^{2}}=\frac{3.8416(0.25)}{0.0025}=326 \text { Woman }
$$


Table 1: Number of women interviewed by health centers

\begin{tabular}{ccccc}
\hline Health center & Women & Women using & Proportion & Women \\
& expected & PF & & interviewed \\
\hline Biryogo & 7915 & 1870 & 0.28 & 92 \\
Gitega & 6909 & 1996 & 0.25 & 82 \\
Kabusunzu & 5704 & 1974 & 0.20 & 66 \\
Muhima & 7508 & 2879 & 0.27 & 86 \\
Total & 28036 & 8719 & 01 & 326 \\
\hline
\end{tabular}

FP: Family Planning

Random sampling technique was adopted; women were randomly selected according to their arrival order at the health center (HC). In total, 326 women distributed proportionally over four HCs, were interviewed in each HC (Table 1). The interview took 5 days. Thus, a systematic sampling technique was adopted by selecting women at regular intervals according to their sitting positions on a particular clinic day. The starting point was chosen at random.

\section{Data Collection}

Women involved in this present study were approached following the order of their arrival for their appointment. The purpose of the present study and its significance was discussed with them; then they were requested to participate voluntarily in the study. Weekly family planning sessions were used to collect data. The researcher personally distributed the data collecting instruments and collected the questionnaires when completed. Confidentiality was ensured. The researcher assigned codes and numbers to each questionnaire and observation. A pre-tested close-ended questionnaire was administered. It was explained in Kinyarwanda to assure better understanding.

\section{Data analysis}

The present study is a descriptive cross-sectional study of women of reproductive age at different health centers located in Muhima health district. We collected, saved, and analyzed data from our sample according to socioeconomic and socio-demographic variables. From this, frequencies for qualitative variables, the mean and the median for the quantitative variables were calculated. Quantitative variables were grouped together to allow us to carry out binary analysis, looking for the association between risk behavior and factors influencing knowledge, attitudes, and determinant on contraceptive use, which is our dependent variable.

To allow us to put in evidence the association between dependent variables and the determinants on use of contraceptive, we used a statistic test for the comparison of proportions. Data analysis was done using SPSS (Statistical Package for Social Science) for close-ended responses; frequency distribution and percentages were used, where appropriate. Each item of the questionnaire was coded (assigned a number). The responses for open-ended questions were 
analyzed using content analysis; all responses were analyzed to establish the main ideas or themes. Then these themes were categorized according to their characteristics and the information from the literature.

\section{Ethical Considerations}

Respondents were required to sign consent forms stating the aims and purpose of the research and requesting participation in the study. Anonymity has been guaranteed. A number was assigned to the questionnaire. The consent was kept separated from the questionnaire to ensure anonymity. The respondents were informed about their right to accept or refuse to give information. They were also informed that they were free to withdraw from research any time they felt like doing so.

\section{Results}

\section{Socio-demographic Variables}

Mean age of the respondents $=28.8, \mathrm{Std}=5.3$ years, minimum $=18$ years, maximum $=48$ years. Number of children: Minimum $=0$, maximum $=7$ children. Table 2 presents the socio-demographic profile of the respondents.

Table 2: Profile of the respondents

\begin{tabular}{|c|c|c|c|}
\hline \multicolumn{2}{|c|}{ Socio-demographic variables } & \multirow{2}{*}{$\frac{\text { Frequency }}{10}$} & \multirow{2}{*}{$\begin{array}{c}\text { Percentage } \\
3.1\end{array}$} \\
\hline Age & 18 to 20 years & & \\
\hline & 21 to 30 years & 219 & 25.9 \\
\hline & 31 to 48 years & 96 & 29.5 \\
\hline & Total & 325 & 100 \\
\hline \multirow[t]{7}{*}{ Marital status } & Single & 09 & 2.8 \\
\hline & Legally married & 182 & 55.8 \\
\hline & Illegally married & 122 & 37.4 \\
\hline & Divorced/separated & 08 & 2.5 \\
\hline & Widowed & 05 & 1.5 \\
\hline & & & 100 \\
\hline & Total & 326 & \\
\hline \multirow[t]{5}{*}{ Education level } & None & 06 & 1.8 \\
\hline & Primary & 160 & 49.2 \\
\hline & Secondary & 149 & 45.8 \\
\hline & University & 10 & 3.1 \\
\hline & Total & 325 & 100 \\
\hline
\end{tabular}




\begin{tabular}{|c|c|c|c|}
\hline \multirow{5}{*}{$\begin{array}{l}\text { The respondent's } \\
\text { profession }\end{array}$} & None & & 41.2 \\
\hline & & 135 & \\
\hline & Private & 148 & 45.5 \\
\hline & Public & 43 & 13.2 \\
\hline & Total & 325 & 100 \\
\hline \multirow[t]{3}{*}{ Number of children } & 0 to 4 children & 296 & 90.8 \\
\hline & 5 to 7 children & 30 & 9.2 \\
\hline & Total & 326 & 100 \\
\hline \multirow[t]{5}{*}{$\begin{array}{l}\text { Monthly income of } \\
\text { the household }\end{array}$} & $\begin{array}{l}\text { Less than } 30,000 \\
\text { RWF }\end{array}$ & 88 & 27.2 \\
\hline & Between 30,000 and & & \\
\hline & 100,000RWF & 216 & 66.7 \\
\hline & $\begin{array}{l}\text { Greater } 100,000 \\
\text { RWF }\end{array}$ & 20 & 6.2 \\
\hline & Total & 324 & 100 \\
\hline \multirow[t]{6}{*}{ Religion } & Adventist & 38 & 11.7 \\
\hline & Catholic & 109 & 33.4 \\
\hline & Muslim & 101 & 31 \\
\hline & Protestant & 75 & 23 \\
\hline & Other (specify) & 03 & 0.9 \\
\hline & Total & 326 & 100 \\
\hline
\end{tabular}

\section{Knowledge}

Table 3 shows that $34.7 \%$ women surveyed were aware of family planning (FP) through different trainings at health centers levels. Other sources of information (media, school, friends) represent 48.8\%. 16.6\% mentioned that they got their knowledge of FP from all sources of information combined.

Table 3: Source of information about family planning

\begin{tabular}{lcc}
\hline Source & Frequency & Percentage \\
\hline Health center & 113 & 34.7 \\
Other & 159 & 48.8 \\
All & 54 & 16.6 \\
Total & 326 & 100 \\
\hline
\end{tabular}




\section{Advantage of Family Planning}

Birth spacing, orderly birth, and healthy child development are the key benefits (Table 4 ) cited by women in our survey $(96.6 \%)$.

Table 4: Advantages of using family planning

\begin{tabular}{lcc}
\hline Advantage & Frequency & Percentage \\
\hline $\begin{array}{l}\text { Space in birth, making orderly } \\
\text { birth }\end{array}$ & 314 & 96.6 \\
$\begin{array}{l}\text { Good growth of the children } \\
\text { Prevention of diseases }\end{array}$ & 01 & \\
Other & 10 & 0.3 \\
Total & 326 & 3.1 \\
\hline
\end{tabular}

\section{Attitude toward Family Planning}

To know the attitudes of women toward FP, they were asked whether they were favorable to FP, if they would encourage other women to use FP, if they think that FP can promote development, and if their religious belief encourages the use of FP. Table 5 summarizes the different reactions of the respondents.

Table 5: Attitudes toward FP

\begin{tabular}{lccc}
\hline Attitudes towards FP & & Frequency & Percentage \\
\hline Are you favorable to FP & Yes & 308 & 97.5 \\
& No & 08 & 2.5 \\
Total & & 316 & 100 \\
Can you encourage other & Yes & 315 & 99.7 \\
women to use FP? & No & 01 & 0.3 \\
Total & & 316 & 100 \\
Do you think that FP can & Yes & 309 & 98.4 \\
promote development? & No & 05 & 1.6 \\
Total & & 314 & 100 \\
Does your religious belief & & 198 & 62.7 \\
encourage FP? & Yes & 118 & 37.3 \\
Total & No & 316 & 100 \\
\hline
\end{tabular}

\section{Practice}

As shown in Table 6, almost all respondents (96.9\%) practice one or other of the family planning methods. Pills and injections are the most practiced methods ( $43.5 \%$ and $42.5 \%$ respectively). Regarding the duration of the FP practice, $45.2 \%$ of women practiced it for at least 2 years; $39.4 \%$ practiced it between 3 and 5 years and $15.4 \%$ for over 5 years. 
Table 6: Practice of family planning

\begin{tabular}{|c|c|c|c|}
\hline FP practice & & Frequency & Percentage \\
\hline \multirow[t]{2}{*}{ FP utilization } & Yes & 313 & 96.9 \\
\hline & No & 10 & 3.1 \\
\hline Total & & 323 & 100 \\
\hline \multirow[t]{5}{*}{ FP methods used } & Natural & 5 & 1.6 \\
\hline & Condom & 7 & 2.2 \\
\hline & Implant & 33 & 10.2 \\
\hline & Pills & 140 & 43.5 \\
\hline & Injection & 137 & 42.5 \\
\hline Total & & 322 & 100 \\
\hline \multirow[t]{3}{*}{ Duration } & $\begin{array}{c}\text { Less than } 2 \\
\text { years }\end{array}$ & 147 & 45.2 \\
\hline & 3 to 5 years & 128 & 39.4 \\
\hline & $\begin{array}{c}\text { More than } 5 \\
\text { years }\end{array}$ & 50 & 15.4 \\
\hline Total & & 325 & 100 \\
\hline
\end{tabular}

\section{Bivariate analysis}

Bivariate analysis allowed us to establish, using the statistical test of chisquare, the bond strength between the socio-demographic independent variables and each of our three dependent variables relating to FP (cf. Tables 7-9). These tests show that only the variable marital status was significantly related to the practice of FP $(p=0.004)$ and FP knowledge $(p=0.01)$. 
Table 7: Summary of bivariate analyses of some independent variables with FP knowledge

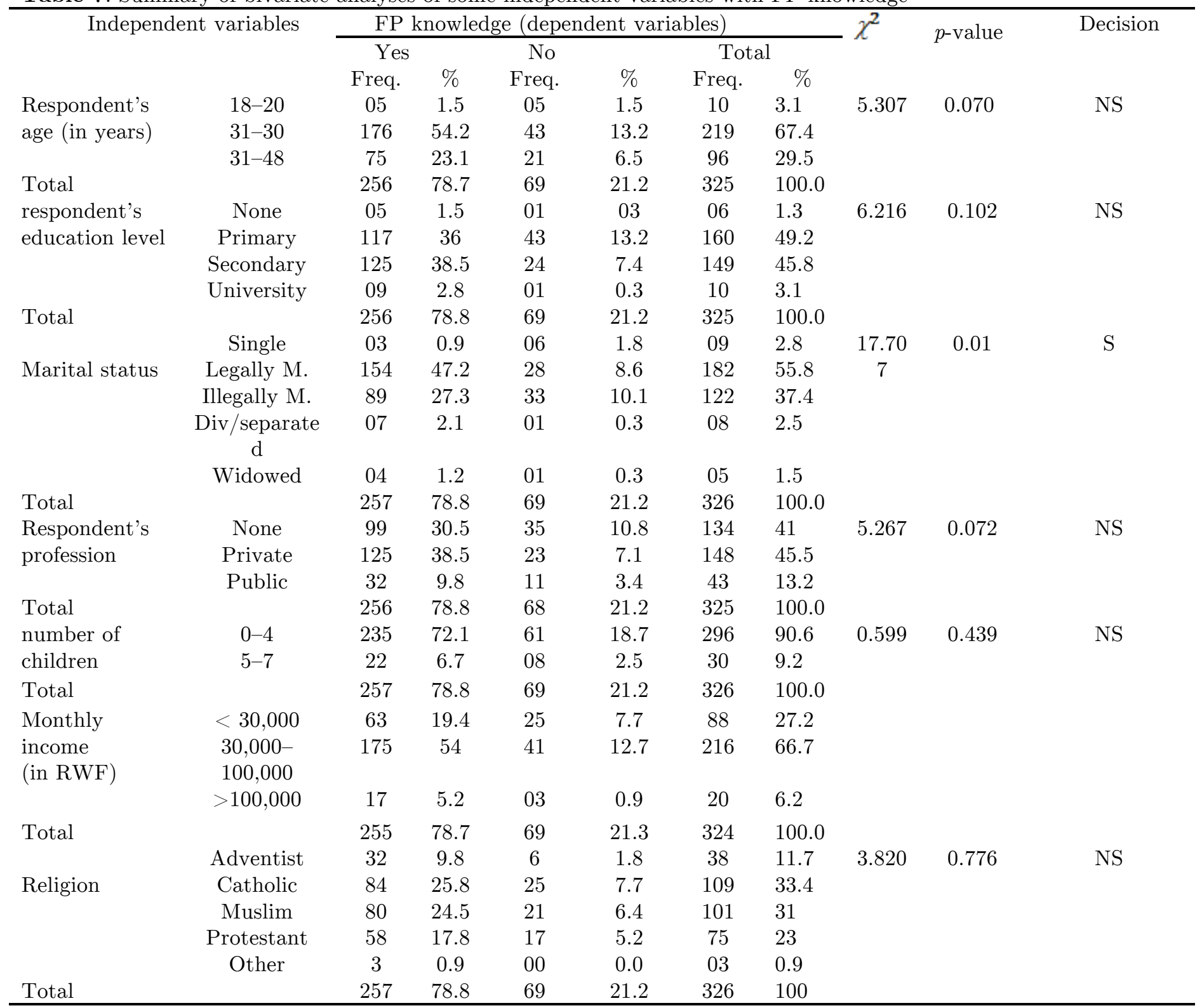

NT: Not Significant

S : Significant 
Table 8: Summary of bivariate analyses of certain independent variables with attitude favorable to FP

\begin{tabular}{|c|c|c|c|c|c|c|c|c|c|c|}
\hline \multicolumn{2}{|c|}{ Independent variables } & \multicolumn{6}{|c|}{ Attitude favorable to FP } & \multirow[t]{3}{*}{$\chi^{2}$} & \multirow[t]{3}{*}{$p$-value } & \multirow[t]{2}{*}{ Decision } \\
\hline & & \multicolumn{2}{|c|}{ Yes } & \multicolumn{2}{|c|}{ No } & \multicolumn{2}{|c|}{ Total } & & & \\
\hline \multirow{4}{*}{$\begin{array}{c}\text { Respondent' } \\
\text { s age (in } \\
\text { years) }\end{array}$} & & Freq. & $\%$ & Freq. & $\%$ & Freq. & $\%$ & & & \multirow{5}{*}{ NS } \\
\hline & $18-20$ & 8 & 2.5 & 1 & 0.3 & 9 & 2.9 & \multirow[t]{4}{*}{3.543} & \multirow[t]{4}{*}{0.170} & \\
\hline & $31-30$ & 207 & 65.7 & 6 & 1.9 & 213 & 7.6 & & & \\
\hline & $31-48$ & 92 & 29.2 & 1 & 0.3 & 93 & 29.5 & & & \\
\hline Total & & 307 & 97.5 & 8 & 2.5 & 315 & 100.0 & & & \\
\hline \multirow{4}{*}{$\begin{array}{c}\text { Respondent' } \\
\text { s education } \\
\text { level }\end{array}$} & None & 6 & 1.9 & 0 & 0 & 6 & 1.9 & \multirow[t]{5}{*}{1.118} & \multirow[t]{5}{*}{0.773} & \multirow[t]{5}{*}{ NS } \\
\hline & Primary & 151 & 47.9 & 3 & 3 & 154 & 46 & & & \\
\hline & Secondary & 140 & 44.4 & 5 & 1.6 & 145 & 46 & & & \\
\hline & University & 10 & 3.2. & 0 & 0.0 & 10 & 3.2 & & & \\
\hline Total & & 307 & 97.5 & 8 & 2.5 & 316 & 100.0 & & & \\
\hline \multirow{5}{*}{$\begin{array}{l}\text { Marital } \\
\text { status }\end{array}$} & Single & 9 & 2.8 & 0 & 0.0 & 9 & 2.8 & \multirow[t]{6}{*}{0.971} & \multirow[t]{6}{*}{0.914} & \multirow[t]{6}{*}{ NS } \\
\hline & Legally M. & 172 & 54.4 & 4 & 1.3 & 176 & 55.7 & & & \\
\hline & Illegally M. & 114 & 36.1 & 4 & 1.3 & 118 & 37.3 & & & \\
\hline & $\begin{array}{c}\text { Div/separate } \\
\text { d }\end{array}$ & 08 & 2.5 & 0 & 0.0 & 8 & 2.5 & & & \\
\hline & Widowed & 05 & 1.6 & 0 & 0.0 & 5 & 1.6 & & & \\
\hline Total & & 308 & 97.5 & 8 & 2.5 & 316 & 100.0 & & & \\
\hline \multirow{3}{*}{$\begin{array}{l}\text { Respondent' } \\
\text { s profession }\end{array}$} & None & 125 & 40 & 4 & 1.3 & 130 & 41.3 & \multirow{4}{*}{$\begin{array}{c}1 . .91 \\
9\end{array}$} & \multirow[t]{4}{*}{0.383} & \multirow[t]{4}{*}{ NS } \\
\hline & Private & 143 & 45.4 & 2 & 0.6 & 145 & 46 & & & \\
\hline & Public & 38 & 12.1 & 2 & 0.6 & 40 & 12.7 & & & \\
\hline Total & & 37 & 97.5 & 8 & 2.5 & 315 & 100.0 & & & \\
\hline \multirow{2}{*}{$\begin{array}{l}\text { Number of } \\
\text { children }\end{array}$} & $0-4$ & 279 & 88.3 & 7 & 2.2 & 286 & 90.5 & \multirow[t]{2}{*}{0.086} & 0.769 & NS \\
\hline & $5-7$ & 29 & 9.2 & 1 & 0.3 & 30 & 9.5 & & & \\
\hline Total & & 308 & 97.5 & 8 & 2.5 & 316 & 100.0 & & & \\
\hline Monthly & $<30,000$ & 83 & 26.4 & 3 & 1.0 & 86 & 27.4 & 5.721 & 0.057 & NS \\
\hline $\begin{array}{c}\text { income } \\
\text { (in RWF) }\end{array}$ & $\begin{array}{l}30,000- \\
100,000\end{array}$ & 204 & 65 & 5 & 1.6 & 209 & 66.6 & & & \\
\hline & $>100,000$ & 19 & 6.1 & 0 & 0.0 & 19 & 6.1 & & & \\
\hline Total & & 306 & 97.5 & 8 & 2.5 & 314 & 100.0 & & & \\
\hline Religion & Adventist & 38 & 12 & 0 & 0.0 & 38 & 12 & 1.916 & 0.751 & NS \\
\hline & Catholic & 100 & 31.6 & 4 & 1.3 & 104 & 32.9 & & & \\
\hline & Muslim & 97 & 30.7 & 2 & 0.6 & 99 & 31.3 & & & \\
\hline & Protestant & 70 & 22.2 & 2 & 0.6 & 72 & 22.8 & & & \\
\hline & Other & 3 & 0.9 & 0 & 0.0 & 3 & 0.9 & & & \\
\hline Total & & 308 & 97.5 & 8 & 2.5 & 316 & 100.0 & & & \\
\hline
\end{tabular}


Table 9: Summary of bivariate analyses of certain independent variables with the practice of FP

\begin{tabular}{|c|c|c|c|c|c|c|c|c|c|c|}
\hline \multirow{3}{*}{\multicolumn{2}{|c|}{ Independent variables }} & \multicolumn{6}{|c|}{ Practice of FP } & \multirow[t]{3}{*}{$\chi^{2}$} & \multirow[t]{3}{*}{$p$-value } & \multirow[t]{3}{*}{ Decision } \\
\hline & & \multicolumn{2}{|c|}{ Yes } & \multicolumn{2}{|c|}{$\mathrm{No}$} & \multicolumn{2}{|c|}{ Total } & & & \\
\hline & & Freq. & $\%$ & Freq. & $\%$ & Freq. & $\%$ & & & \\
\hline Respondent' & $18-20$ & 9 & 2.8 & 0 & 0.0 & 9 & 2.8 & 0.764 & 0.682 & NS \\
\hline s age (in & $31-30$ & 212 & 65.8 & 6 & 1.9 & 218 & 67.7 & & & \\
\hline years) & $31-48$ & 91 & 28.3 & 4 & 1.2 & 95 & 29.5 & & & \\
\hline Total & & 312 & 96.9 & 10 & 3.1 & 322 & 100.0 & & & \\
\hline \multirow{4}{*}{$\begin{array}{c}\text { Respondent' } \\
\text { s education } \\
\text { level }\end{array}$} & None & 6 & 1.9 & 0 & 0.0 & 6 & 1.92 & 2.059 & 0.560 & NS \\
\hline & Primary & 150 & 46.6 & 7 & 2.22 & 157 & 48.8 & & & \\
\hline & Secondary & 146 & 45.6 & 3 & 0.92 & 149 & 46.3 & & & \\
\hline & University & 10 & 3.1 & 0 & 0.0 & 10 & 3.1 & & & \\
\hline \multirow{2}{*}{ Total } & & 312 & 96.9 & 10 & 31 & 322 & 100.0 & & & \\
\hline & Single & 8 & 2.5 & 1 & 0.3 & 9 & 2.8 & 15.50 & 0.004 & S \\
\hline \multirow{4}{*}{$\begin{array}{l}\text { Marital } \\
\text { status }\end{array}$} & Legally M. & 178 & 55.1 & 4 & 1.2 & 182 & 56.3 & 1 & & \\
\hline & Illegally M. & 116 & 35.9 & 3 & 0.9 & 119 & 36.8 & & & \\
\hline & $\begin{array}{c}\text { Div/separate } \\
\text { d }\end{array}$ & 6 & 1.9 & 2 & 0.6 & 8 & 2.5 & & & \\
\hline & Widowed & 5 & 1.5 & 0 & 0.0 & 5 & 1.5 & & & \\
\hline \multirow[t]{2}{*}{ Total } & & 313 & 96.9 & 10 & 31 & 323 & 100.0 & & & \\
\hline & None & 130 & 40.4 & 3 & 0.9 & 133 & 31.3 & 0.895 & 0.639 & NS \\
\hline Respondent' & Private & 140 & 43.5 & 6 & 1.9 & 146 & 45.3 & & & \\
\hline s profession & Public & 42 & 13 & 1 & 0.3 & 43 & 13.4 & & & \\
\hline Total & & 312 & 96.9 & 10 & 3.1 & 322 & 100.0 & & & \\
\hline \multirow{2}{*}{$\begin{array}{l}\text { Number of } \\
\text { children }\end{array}$} & $0-4$ & 283 & 87.6 & 10 & 3.1 & 293 & 90.7 & 1.057 & 0.303 & NS \\
\hline & $5-7$ & 30 & 9.3 & 0 & 0.0 & 30 & 9.3 & & & \\
\hline Total & & 313 & 96.9 & 10 & 3.1 & 323 & 100.0 & & & \\
\hline Monthly & $<30,000$ & 82 & 25.5 & 6 & 1.9 & 88 & 27.4 & 5.721 & 0.057 & NS \\
\hline \multirow[t]{2}{*}{$\begin{array}{l}\text { income (in } \\
\text { RWF) }\end{array}$} & $\begin{array}{l}30,000- \\
100,000\end{array}$ & 209 & 65.1 & 4 & 1.2 & 213 & 66.1 & & & \\
\hline & $>100,000$ & 20 & 6.2 & 0 & 0.0 & 20 & 6.2 & & & \\
\hline \multirow[t]{2}{*}{ Total } & & 311 & 96.9 & 10 & 3.1 & 321 & 100.0 & & & \\
\hline & Adventist & 38 & 11.8 & 0 & 0.0 & 38 & 11.8 & 1.783 & 0.776 & NS \\
\hline \multirow[t]{4}{*}{ Religion } & Catholic & 104 & 32.2 & 4 & 1.2 & 108 & 33.4 & & & \\
\hline & Muslim & 95 & 29.4 & 4 & 1.2 & 103 & 30.7 & & & \\
\hline & Protestant & 73 & 22.6 & 2 & 0.6 & 75 & 23.2 & & & \\
\hline & Other & 3 & 0.9 & 0 & 0.0 & 3 & 0.9 & & & \\
\hline Total & & 313 & 96.9 & 10 & 3.1 & 323 & 100.0 & & & \\
\hline
\end{tabular}

\section{Discussion}

The result in this present study can be classified under four items: sociodemographic variables, knowledge of respondents on FP, the respondents' attitudes on FP, and the practice of FP.

\section{Socio-demographic Variables}

Age is a fundamental variable in analyzing demographic phenomena; but it is one of the most difficult to obtain when written records of events (especially civil status data) are far from exact. Special efforts were made in individual questionnaires to record respondents' correct age. Respondents were asked for both their date of birth and their age. We then checked the two pieces of 
information for consistency. In cases where the respondent did not know her birth date or her age, we sought to obtain the information by looking at an official document (identity card, etc.) or by calculating the date of birth. If no official documents were available, we confirmed the age information provided by the respondent by referring to major life events (age at marriage, age of first child, etc.) or well-known national or regional events.

For the age of the respondents: Mean $=28.8$, std $=5.3$ years, minimum $=$ 18 , maximum $=48$ years. For number of children: Minimum $=0$, maximum $=7$ children.

\section{Knowledge}

We found that among the participants, knowledge of family planning method is high in the study area. In addition, the majority of participants reported that family planning methods are available at their health centers. Furthermore, respondents reported that a variety of family planning methods are available at the health facilities including oral contraceptive pills, injectables, condoms, insertions, and spermicides.

A similar study of family planning programs in India's rural Bihar state indicated that improved access to services, expanded choice of available methods, and increased knowledge of family planning were important for the acceptance of contraception. However, opposition from husbands and in-laws, the desire for at least two sons, and lack of trust of voluntary health workers from different races/classes or religion were obstacles to the acceptance of contraception [7]. As indicated in the table three $34.7 \%$ women surveyed were aware of FP through different trainings at health centers levels of this analysis. In comparison to the study conducted in Ethiopian in 2012 by USAID, Ethiopia Federal Ministry of Health, Partners in Population development and Health Policy Project, woman bears an average of five children in her lifetime, the study shows that in 2011, $29 \%$ of married Ethiopian women of childbearing age (15-49) use any method of family planning [8].

\section{Attitude toward Family Planning Methods}

Attitudes toward the idea of avoiding pregnancy and specific methods of contraception are no doubt multidimensional and a statement of mere approval or disapproval fails to capture this complexity or the underlying reasons. Nevertheless, trends in approval as measured by identical questions in our survey has revealed how contraception has gone from being perceived as an alien, socially deviant practice that threatens health and undermines religious beliefs to being a routine, uncontroversial aspect of married life. Ability, or access, is similarly complex, with social as well as spatial components. The indicator of ability used in this paper, i.e., familiarity with some specific modern methods of contraception and where to obtain them, captures the most fundamental components of access.

Almost all women surveyed (97.5\%) had a favorable attitude toward the practice of FP methods as it has been mentioned in Table 5 of this present study. Almost all women surveyed confirmed to have the will to encourage their neighbors to practice FP. The comparison percentage results of this present study is far better than the results reported in a similar study in Nigeria (27.1\%) [9]. 
The results of this present study indicated that men often have positive attitudes toward family planning, but women believe that their husbands disapprove of family planning. The report further noted that spousal communication was positively associated with family planning method use (Toure, 1996). However, another study conducted by Ezeh (1993) in Ghana indicated that spousal influence, rather than being mutual or reciprocal, is an exclusive right of the husband. According to the Demographic and Health Surveys, many married women who wanted to avoid pregnancy are not using contraception because their husband objects. Nearly one in ten married women with unmet need cited husband's disapproval as the principal reason for nonuse of contraception [10].

\section{Practice}

Almost all respondents $(96.9 \%)$ practicing family planning state that they practice one or other method at any given point in time. Pills (43.5\%) and injections $(42.5 \%)$ were the methods most commonly practiced in the health centers in this present study.

Regarding the duration of the practice of one or another FP method, $45.2 \%$ of women practiced it for at least 2 years; $39.4 \%$ practiced it between 3 and 5 years and $15.4 \%$ for over 5 years. Among the women surveyed, $13.9 \%$ said that they had complications related to the practice of FP.

Among these complications, they cited: Headache, pain in lower abdomen, weight gain, and menstruation that does not stop. This situation has been reported in surveys done in India and China on PF methods in urban areas where 13 women believed that the practice of FP leads to lower abdomen pain [11].

This shows that readiness to use family planning is the subjective need or desire to postpone births or cease childbearing altogether. These are not the only reasons for using contraception, but they are clearly the most common. Willingness refers to an attitude in favor of contraception and of certain contraceptive methods in particular.

In many societies, resistance to modern contraception is common at first and takes the form of outright refusal, for religious or cultural reasons or because of the fear of becoming sterile and other health concerns. Qualitative research in Africa has documented deep-seated resistance to the use of modern contraception [12].

Ability refers to being familiar with contraceptive methods and their supply sources and having reasonable access to them. Readiness, willingness, and ability are obvious preconditions for use and the three elements interact. For instance, readiness may lead a woman to learn about methods and supply sources. However, no assumptions about causal ordering can be made. 


\section{Conclusion and Recommendations}

\section{Conclusion}

Rwandan women have not fully embraced family planning as a method of contraception as they traditionally accept child bearing as a source of pride and respect of their womanhood. Rumors and misconceptions about contraceptives, and fear of side effects were common.

But a massive effort is underway to educate communities, men as well as women, about the value of smaller families. The government is very conscious of demographic trends. Some overall strategies to address the unmet need for family planning are recommended, based on the findings of this present study. Education contributes significantly to the quality of women's lives.

According to this present study, the participants' knowledge of family planning method is high in the study area. $78.8 \%$ of the women surveyed were aware of FP methods through different trainings at health centers level. In addition, the majority of participants reported that family planning methods are available at their health centers.

Furthermore, $98.4 \%$ were favorable to family planning methods and think that FP can promote development. Almost all respondents (96.9\%) practice one of the family planning methods.

However, more than half of the respondents said they did not use the methods of family planning which were seen as a negative point in terms of family planning.

In the point of view, Family Planning programs can have long-term consequences for economic growth, including reduced fertility and population growth, and the well-being of child survival, schooling of children and family health.

The UN 1994 Population Conference in Cairo concluded that family planning enhanced women's health and empowerment.

\section{Recommendations}

To the government:

Improve access to services, expanded choice of available methods, and increased knowledge regarding family planning; improve women's access to education;

Continuously encourage and train health service providers for effective promotion of family planning;

Encourage spousal communication and involve men in family planning decision making in order to bridge the gap between met and unmet need.

To healthcare providers:

Programs designed to meet women's need for family planning in Rwanda should also devise strategies to address spacing and limiting needs differently, and target women accordingly;

Community based family planning services need to be more expanded and strengthened in rural Rwanda so as to disseminate information, education, and 
counseling on family planning and provide services to the needy, especially to the unreached and underserved populations;

By bringing family planning services closer to users, it would be possible to improve accessibility and availability of contraceptives.

To women:

Women using contraceptive methods should look for assistance to the service providers when they face side effects due to the use of one of the family planning methods.

To researchers:

More performance assessment studies are needed to be carried out in Rwanda to show substantial increase in the prevalence of contraceptive use in rural areas.

\section{Acknowledgement}

We sincerely thanks to the whole team working for completion of this present study, despite the fact, their commitments for this work was successfully. We offer our appreciation to the men and women who will use this paper, we hopefully they will understand the ultimate aim of the production of this present study.

\section{Authors 'Contributions}

-Kanyange Phoibe, Bsc, MPH; participated in the data collection, took part in the analyses and interpretation, conducted the literature search and review and wrote the first draft of the paper.

-Tegera Mpamya Frederic BSc, MPH; conceived, designed and coordinated the study, and critically revised the paper, and review and wrote the first draft of the paper and corresponding author of the paper .

-Joseph Ntaganira MD, DTM, MPH, PhD, Associate Professor; participated in the design of the study and the statistical analysis, and critically revised the paper and analytically reviewed the study for significant intellectual contents.

All authors read and approved the final paper.

\section{Competing interest}

Authors have declared that there is no conflict of interests exist. 


\section{References}

[1] Ministry of Health (2009), Status of Newborn and Child Survival in Rwanda. March: Kigali.

[2] Federal Ministry of Health (2005). Revised National Health Policy Abuja: Federal Ministry of Health.

[3] UNFPA. Reproductive Health: Ensuring that Every Pregnancy is wanted. [on line]. [retrieved on 09-04-2011]: Available at URL : http://www.unfpa.org/rh/planning.htm.

[4] UNFPA. Reproductive Health: Ensuring that Every Pregnancy is wanted. [on line]. [retrieved on 09-04-2011]: Available at URL : http://www.unfpa.org/rh/planning.htm.

[5] Effie K. Chipeta, Wanangwa Chimwaza and Linda Kalilani-Phiri. Contraceptive Knowledge, Beliefs and Attitudes in Rural Malawi: Misinformation, Misbelieves and Misperceptions. MMJ [online]. 2010 June [Retrieved on 6 October 2011]; 22(2): [4 pages]. Available at URL: http://www.mmj.medcol.mw.

[6] Ministry of Health of Rwanda (2009). Rwanda Interim Demographic and Health Survey 2007-8. National Institute of Statistics of Rwanda. Kigali.

[7] Gloria Ekpo, Issakha Diallo (2009). Healthy Timing and Spacing of Pregnancy (HTSP): Operationalization through Integration.

[8] USAID, Federal Ministry of Health Ethipoia, Parteners in Population development, Health Policy Project (2012) Family Planning in Ethiopian

[9] Mushinski, M. (1996) Average charges for uncomplicated vaginal, cesarean and VBAC deliveries: Regional variations, United States. Statistical Bulletin 79(3): 17-28. PMID 9691358.

[10] Ministry of Health. Rwanda Interim Demographic and Health Survey, 2007-08, National Institute of Statistics of Rwanda: Kigali. April 2009.

[11] Rudranand, P., R. Bachan, M. Khan, and B. Patel. (1995) Promotion of FP/MCH care through dairy cooperatives in rural Bihar. New Delhi: Population Research Center (Patna), Institute of Psychological Research and Services (Patna), and the Population Council.

[12] Drennan, M.(1998). Reproductive health: New perspectives on men's participation. Population Reports, Series J, Number 46. Johns Hopkins University School of Public Health, Population Information Program. Baltimore, Maryland USA. 